\title{
Sustainable Higher Education Development through Technology Enhanced Learning
}

\author{
Javier Orozco-Messana ${ }^{1, * \mathbb{C}}$, Juan Miguel Martínez-Rubio ${ }^{2}$ and Ana Maria Gonzálvez-Pons ${ }^{1}$ \\ 1 ITM, Universitat Politecnica de Valencia, 46022 Valencia, Spain; angonpon@upvnet.upv.es \\ 2 DISCA, Universitat Politecnica de Valencia, 46022 Valencia, Spain; jmmr@upv.es \\ * Correspondence: jaormes@cst.upv.es
}

Received: 2 April 2020; Accepted: 28 April 2020; Published: 29 April 2020

\begin{abstract}
Higher education is incorporating Information and Communication Technology (ICT) at a fast rate for different purposes. Scientific papers include within the concept of Technology Enhanced Learning (TEL) the myriad applications of information and communication technology, e-resources, and pedagogical approaches to the development of education. TEL's specific application to higher education is especially relevant for countries under rapid development for providing quick and sustainable access to quality education (UN sustainable development goal 4). This paper presents the research results of an online pedagogical experience in collaborative academic research for analyzing good practice in TEL-supported higher education development. The results are obtained through a pilot implementation providing curated data on TEL competency's development of faculty skills and analysis of developing sustainable higher education degrees through TEL cooperation, for capacity building. Given the increased volume and complexity of the knowledge to be delivered, and the exponential growth of the need for skilled workers in emerging economies, online training is the most effective way of delivering a sustainable higher education. The results of the PETRA Erasmus+ capacity-building project provides evidence of a successful implementation of a TEL-supported methodology for collaborative faculty development focused on future online degrees built collaboratively and applied locally.
\end{abstract}

Keywords: technology enhanced learning; sustainable on-line education; capacity building

\section{Introduction}

The virtualization of society thanks to the Internet and the wide availability of sophisticated devices, is making higher education evolve everywhere. TEL is now embedded into all types of universities-digitalizing contents, changing methodologies, and facilitating the quality implementation of TEL into all types of degrees. [1] New technology-native generations and the ubiquity of the Internet, has made traditional delivery of contents obsolete thanks to the flexibility and accessibility of contents fulfilling instantly individual requirements. Methodologies are increasingly dynamic and with a modular structure based on instant consumption for different uses and environments. Innovation is developing university courses hugely, [2] a tendency that is giving birth to an exponential availability of e-courses and materials. Beyond mere tools, TEL applications allow fast capacity building into young faculty and collaborative (open) schemes for implementing methodologies and contents, [3] and achieving excellent results which can be deployed with a small fraction of the resources traditionally required for University education. Existing open-source education platforms can be implemented easily with a significant improvement of students' performance and levels and engagement with very limited resources. [4]

Collaborative schemes and capacity-building initiatives enhance the quality development of learning resources (contents), teaching tools (systems), and proven practices. These facts, together with 
low-cost Internet and ubiquitous tablets (or cell phones), are a very attractive alternative to traditional learning for fast-growing societies with limited resources [5]. The Internet has changed timing, access to knowledge, and learning processes [6]. Once presential limitations are abolished, students are empowered to manage their time schedules and pacing [7]. Faculty is then faced with a different scenario for tracking progress and assessing evaluation, which needs to be adapted to individual progress [8].

Through a review of TEL literature research [9] we can assume that TEL comprises much more than facilitating tools. The possibilities of technology applied to learning should be addressed through their core nature values for augmented learning. The main focal points of this approach are information handling, learning process management, knowledge building supervision, and collaborative development.

Considering education as a system, information is our input, while knowledge acquisition is the output obtained through the teaching process. In this model, native TEL values of inexpensive data handling, instant communication, and information access should be addressed as the main values for TEL programs.

The implementation of a TEL strategy allows a quick and sustainable development of higher education with a wide outreach, but requires adequately prepared academics and collaboration [9]. For bridging this gap, the PETRA Erasmus+ capacity-building project was designed to develop a methodology allowing a quick launch of cooperative TEL implementation in Azerbaijan.

Oil and natural gas exports have helped make Azerbaijan the most prosperous state in the Caucasus region. The post-Soviet Union era was a difficult transition period, which started to flourish after 2003. Economic independence favored an approach to the EU culminating in the signature of the Bologna Agreement in 2005. The new 2009 education law nominally introduced the European Credit Transfer System in the country. University bachelor degrees are three years, and postgraduate master's programs are two years, followed by $\mathrm{PhD}$ and Sc.D doctoral degrees.

From October 2013, the economic development brought different strategic plans, which aim to bring about a full reform by 2025 . The strategy was created in compliance with a holistic and open approach to education and its development, which allowed a higher level of collaboration with the European Union. The strategic development goals are:

- Content development for a competency-based education, incorporating best practices from the most advanced universities, their key academics, and establishing a Professional Learning Community (PLC).

- Developing this PLC community through the use of pilot academic programs, and experiencing student development and motivation within Azerbaijan's top universities. This will develop a new innovative education system tested on reference development academic programs for the country.

- Qualification of the public policy administration based on state-business partnerships for following stakeholders' guidelines and need.

- Creating a new mechanism for sustainable higher education development to meet ethics and regulations.

- Creation of modern education infrastructure that ensures TEL development.

These goals meet the same conclusions summarized by Lai et al [10], only adding the necessary infrastructure which will allow collaboration and early deployment, but under Passey premises. [9]

The PETRA project was based on these principles for the development of a TEL strategy in selected Azerbaijan Universities (8) in a cooperative way with five EU universities. Selected faculty teams (following the Ministry criteria) were selected for incorporating through TEL the basic competencies required for replicating the methodology into official curriculums in Azerbaijan.

This paper introduces a pilot academic implementation of the resources developed through PETRA into a virtual collaborative master's-level research project, constructed incorporating 
individual work (each student thesis) as complementary elements of the project. The pilot technical design and implementation presents an excellent practice for collaborative TEL-based higher education development.

\section{Background Literature Review}

According to recent literature analyzing successful results of TEL higher education implementations, the proposed research background builds its design on the key elements for efficient virtual higher education excellence factors in order to define a pilot strategy.

According to Fazil et al. [1] the acceptance of TEL in education requires motivation, an anxiety-free experience, and perceived efficiency — which are centered first on the learning management system [4]. The deployment of higher education online learning should then be centered on efficient and inspiring implementation, which requires leadership.

Graham's review [7] of learning systems identifies motivation with cultural context and learner's pacing control, and how a supervisor's leadership can support the process. All these elements are studied on the Purdue team coordinated by Lee [8] who conclude that a TEL program undertaken from motivation and carried out with leading supervision, also requires the development of learning strategies based on the learners' personal evaluation of the results efficacy, and high task value.

This literature background supports the design of this paper's research on the efficiency of TEL for collaborative academic research project development.

\section{Materials and Methods}

\subsection{Reference Information and Methodology Design}

There are 51 higher education institutions in Azerbaijan, 40 out of them public (state) and 11 private. The actual number of students active in these universities (2019) is presented in Table 1.

Table 1. Key figures for Azerbaijan higher education institutions.

\begin{tabular}{ccccc}
\hline $\begin{array}{c}\text { Type of } \\
\text { Institution }\end{array}$ & $\begin{array}{c}\text { Students } \\
\text { (Number) }\end{array}$ & $\begin{array}{c}\text { Foreign Students } \\
\text { (Number) }\end{array}$ & $\begin{array}{c}\text { Permanent Faculty } \\
\text { (Number) }\end{array}$ & $\begin{array}{c}\text { Temporary Faculty } \\
\text { (Number) }\end{array}$ \\
\hline Public & 164,516 & 5897 & 12,494 & 1279 \\
Private & 18,569 & 540 & 2039 & 437 \\
Total & 183,085 & 6437 & 14,533 & 1927 \\
\hline
\end{tabular}

Starting from this objective population, top universities were addressed, and only participants with a reasonable English language qualification could be selected for the required EU collaboration. The Professional Learning Community (PLC) addressed eight universities (PETRA Azerbaijan partners) all through the country (public and private) representing $22 \%$ of the faculty population. Only the best prepared for starting this pilot project were selected. Since the Ministry objectives addressed the same results from Lai et al, [10] the PLC was established based on the requirements presented on attitude [11] and abilities [12] to meet the challenge (and English language proficiency). The PLC team (and students) is shown in Table 2 (basis for the research). 
Table 2. Professional Learning Community (PLC) team distribution per university, and academic level.

\begin{tabular}{ccccc}
\hline Institution/Academic Level & \multirow{2}{*}{ Master's Students } & \multicolumn{2}{c}{ Faculty } & \multirow{2}{*}{ Total } \\
\hline Khazar University & & 6 & 2 & 16 \\
Ganja State University & 8 & 7 & 2 & 15 \\
Nakchivan State University & 6 & 6 & 1 & 12 \\
Sumgait State University & 5 & 5 & 1 & 11 \\
Baku Slavic University & 5 & 4 & 2 & 12 \\
Azerbaijan University of Languages & 6 & 4 & 2 & 10 \\
Azerbaijan State Pedagogical University & 4 & 5 & 3 & 13 \\
Azerbaijan University & 5 & 5 & 2 & 14 \\
\hline Total & 7 & 42 & 15 & 103 \\
\hline
\end{tabular}

The pilot academic program under study develops a collaborative proposal for addressing student research projects through multidisciplinary teams. In other words, different teams of the faculty (EU facilitator and Azerbaijan supervisors) and master's students worked on six teams for the co-development of their final thesis. The purpose was twofold: a pedagogic innovation on collaborative research teamwork, and a technical implementation based on TEL innovation tools. The proposed TEL implementation is designed to answer the objectives proposed through the following research questions:

- How can we implement online collaborative research for excellent results using TEL tools? Technical design of the pilot includes: pedagogical approach, academic and electronic contents structure (pedagogical innovations), a common learning platform, and a deployment plan (academic requirements) for launching a pilot test for future online degrees.

- Contents were prepared by the PLC. All PLC supervisors participated on the development of all courses co-designing contents, with EU partners' support, and incorporating the lean principles developed by Ely [12] on the new programs.

○ The selected learning platform was Moodle for its widespread use, open-source nature and flexibility. After the course's design, test runs were implemented in eight Teaching and Learning Centers (TLCs) funded through the Erasmus+ program.

- The TLC plan scheduled the courses following the requirements of the pilot. During the test-run deliveries, the PLC team performed a recurrent PDCA (Plan-Do-Check-Act) cycle, providing a framework for continuous feedback and analysis developed later.

- Did the pilot introduce an efficient innovation? For performance assessment, the DeLone and McLean model [13] was selected for building the PETRA pilot and designing data gathering for assessment. The TEL system model includes all stages on the teaching/learning process. This model [12] is applied to the PETRA pilot in Figure 1. Three independent variables under the "quality" heading are identified: content incorporating the standards required for user efficient performance; TEL (TLC) system accessibility assessment (from the technology perspective); standardization of its structure for portability and stability; and last by not least, the implementation developed on each TLC for the pilot evaluated the structure design and correct pedagogical approach. 


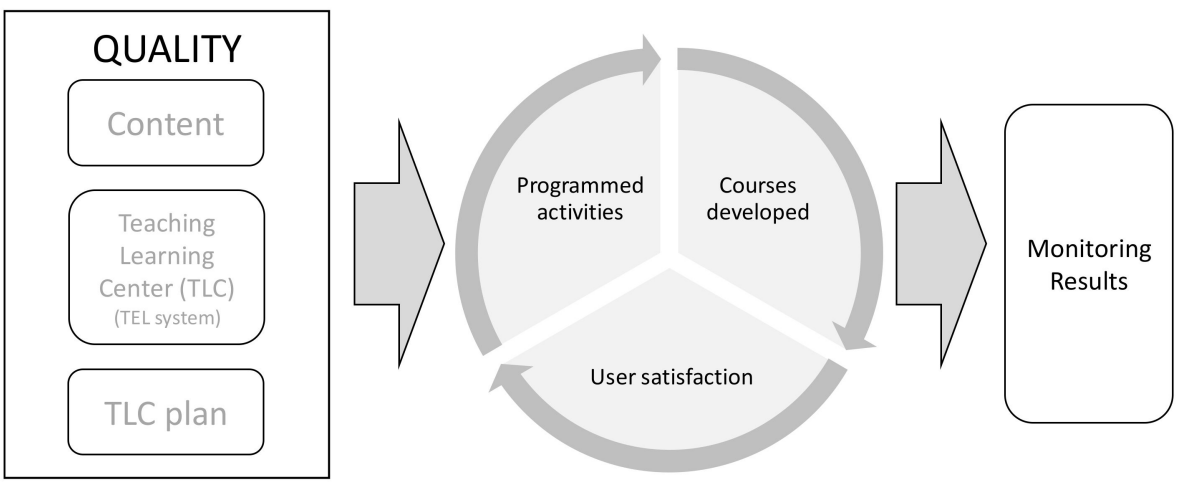

Figure 1. The DeLone and McLean model applied to the PETRA project.

\subsection{Methods and Proposed Research}

The research's background critical requirements are based on the efficiency of the pilot results. Through a careful literature analysis on how to assess TEL efficiency, the selected approach follows Goodman et al. [14] who demonstrate how TEL education can provide excellent results if the following three steps are met:

- Efficacy of knowledge acquisition: According to Alexander et al. [15] best results are obtained by paying special attention to the synthesis performed by students. Therefore, a program design should be focused on the development of systems and emphatic thinking.

- Effective course design: Metacognition progress is the key element to consider when designing an effective use of TEL tools [16].

- Efficient use of resources: The literature analysis review performed by Sun et al. [17] concludes that the combination of content delivery with group project development provides the most significant results.

Following these guidelines, the research methodology based on the DeLone and McLean model [13] was adopted. This model identifies seven check points: needs analysis; course design; usability assessment; implementation analysis; participant assessment; learning outcomes acquisition; and sustainability (including evaluation of cost and reusability).

In the following paragraphs we identify the assessment methods used for each category, grouped per research question, and identifying the quality standards and approaches supporting the instruments used in each case for assessing the experiences of learners and instructors using TEL. The pilot online collaborative research using TEL tools is assessed by:

- Needs analysis: Following the digital education action plan adopted by the EU Commission [18] the current situation of TEL in Azerbaijan was assessed. The most relevant finding was the need for a skilled academic staff task force through blended learning, and the selection of the most urgent topics:

$\bigcirc \quad$ Innovative pedagogies and curriculum design.

$\bigcirc \quad$ Cooperation on high-quality development of research skills.

- Course design: The course model template was taken from the Erasmus+ KA2 project Essence, [19] which was selected for academic staff training due to its successful implementation in Vietnam. The design included five days' full-time work (one per week) for avoiding conflicts with the baseline activities from all participants. Nobody traveled (except for the final presentations and evaluation), and used TEL as the unique support vehicle both in teaching and learning. Regarding capacity-building, key points for the lectures on each course were identified from the needs analysis. Interaction and applicability were guaranteed thanks to the debate methodology. The structure is presented in Figure 2. 
- Usability assessment: Fulfillment of requirements from ISO 9241.

- Implementation analysis and participant assessment: These dimensions were assessed jointly by workshop participants (Azerbaijan faculty) and facilitators (EU faculty). The protocol offered by Lönngren et al. [20] was used as described on the application to transdisciplinary group work by Orozco et al. [[21]

Systems thinking: reading, reflecting, and problematization.

Empathic thinking: free solutions and role play.
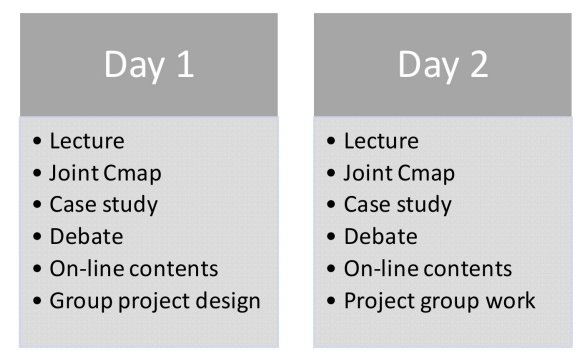
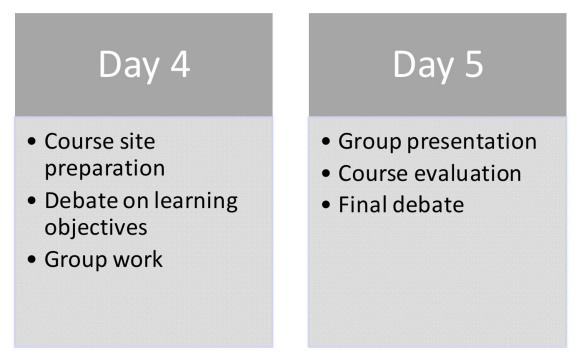

Figure 2. Course design.

The course efficiency evaluation participants were divided into groups ( $3-5$ faculty members each) and their discussions were recorded for analysis. Each group included participants from different institutions and one EU faculty as secretary. Each discussion lasted approximately 30 to 45 minutes. Questions were discussed in each group, which were developed according to the methodology developed in [21]. The corresponding checkpoints for the second research question are:

- $\quad$ Learning outcomes.

- Sustainability.

\subsection{Research Procedure}

The needs analysis, course design, usability assessment, and sustainability of our PETRA (TEL) pilot have already been introduced and their formal implementation courses are already available and offered through the eight TLCs and their action plans. All the PLCs have additional courses on the TLC plan, which can be followed if required. The development of the six research projects for the student/supervisors/EU facilitator groups were hosted in all TLCs. Additionally, there was a usability validation (after ISO9241) for all courses and project materials.

The efficiency evaluation was performed after the course was finished. Azerbaijan participants (faculty and students) answered a post-workshop e-survey, as described in [22]. The survey covered all relevant topics related to effective learning outcomes acquisition determining each student's level of metacognition and interdisciplinarity. The purpose of the survey was to use self-assessment as the true measure of knowledge and awareness developed through TEL by participants.

At the last stage the sustainability of the TEL included a guided debate to assess user satisfaction and the quality of the learning outcomes. The actual deployment of the courses (the result of this TEL experience) will be measured by the TLC plan deployment, where the courses will be available, and their participation (satisfaction) rates. Further to these results, policy measures by the Ministry of Education of the Azerbaijan Republic-including the implementation of academic degrees using the proposed TEL design - will be the final proof of concept. 


\section{Results}

The e-surveys offered quantitative information on the implementation analysis and participation assessment. The graphs presented on the next pages compile average information for all groups, while the group variability is considered by the dispersion coefficient among the groups presented in Table 3 . The internal group dispersions and the average dispersions among groups are both below $10 \%$ in all cases.

Table 3. Average values per dimension with their dispersion coefficients.

\begin{tabular}{ccccccc}
\hline TLC & \multicolumn{2}{c}{$\begin{array}{c}\text { Systems Thinking } \\
\text { Read/Refl. }\end{array}$} & $\begin{array}{c}\text { Empathic Thinking } \\
\text { Problem }\end{array}$ & Free & $\begin{array}{c}\text { Learning } \\
\text { Role }\end{array}$ & $\begin{array}{c}\text { TLC } \\
\text { Outcomes }\end{array}$ \\
& Average \\
\hline Khazar University & $4^{\prime} 28 \pm 0^{\prime} 24$ & $4^{\prime} 48 \pm 0^{\prime} 27$ & $4^{\prime} 40 \pm 0^{\prime} 26$ & $4^{\prime} 44 \pm 0^{\prime} 26$ & $4^{\prime} 08 \pm 0^{\prime} 21$ & $4^{\prime} 34 \pm 0^{\prime} 16$ \\
Ganja St. University & $4^{\prime} 03 \pm 0^{\prime} 24$ & $4^{\prime} 33 \pm 0^{\prime} 26$ & $4^{\prime} 11 \pm 0^{\prime} 21$ & $4^{\prime} 16 \pm 0^{\prime} 23$ & $4^{\prime} 13 \pm 0^{\prime} 22$ & $4^{\prime} 15 \pm 0^{\prime} 11$ \\
Nakchivan St. University & $4^{\prime} 16 \pm 0^{\prime} 23$ & $4^{\prime} 41 \pm 0^{\prime} 26$ & $3^{\prime} 68 \pm 0^{\prime} 16$ & $3^{\prime} 68 \pm 0^{\prime} 16$ & $3^{\prime} 96 \pm 0^{\prime} 19$ & $3^{\prime} 98 \pm 0^{\prime} 31$ \\
Sumgait St. University & $4^{\prime} 34 \pm 0^{\prime} 24$ & $4^{\prime} 22 \pm 0^{\prime} 23$ & $4^{\prime} 88 \pm 0^{\prime} 28$ & $4^{\prime} 28 \pm 0^{\prime} 24$ & $3^{\prime} 82 \pm 0^{\prime} 18$ & $4^{\prime} 31 \pm 0^{\prime} 38$ \\
Baku Slavic University & $4^{\prime} 14 \pm 0^{\prime} 25$ & $4^{\prime} 42 \pm 0^{\prime} 28$ & $4^{\prime} 41 \pm 0^{\prime} 26$ & $4^{\prime} 23 \pm 0^{\prime} 21$ & $3^{\prime} 96 \pm 0^{\prime} 20$ & $4^{\prime} 23 \pm 0^{\prime} 19$ \\
Azerbaijan U. of Languages & $4^{\prime} 24 \pm 0^{\prime} 23$ & $4^{\prime} 32 \pm 0^{\prime} 25$ & $3^{\prime} 98 \pm 0^{\prime} 20$ & $3^{\prime} 57 \pm 0^{\prime} 14$ & $3^{\prime} 85 \pm 0^{\prime} 18$ & $3^{\prime} 99 \pm 0^{\prime} 30$ \\
Azerbaijan St. Pedag. U. & $4^{\prime} 50 \pm 0^{\prime} 27$ & $4^{\prime} 41 \pm 0^{\prime} 27$ & $4^{\prime} 20 \pm 0^{\prime} 22$ & $3^{\prime} 89 \pm 0^{\prime} 19$ & $3^{\prime} 56 \pm 0^{\prime} 17$ & $4^{\prime} 11 \pm 0^{\prime} 39$ \\
Azerbaijan University & $4^{\prime} 44 \pm 0^{\prime} 26$ & $4^{\prime} 32 \pm 0^{\prime} 25$ & $4^{\prime} 11 \pm 0^{\prime} 21$ & $4^{\prime} 40 \pm 0^{\prime} 25$ & $4^{\prime} 03 \pm 0^{\prime} 21$ & $4^{\prime} 26 \pm 0^{\prime} 18$ \\
\hline
\end{tabular}

Through the following graphs, a quantitative analysis of the previously identified requirements for the implementation and participant assessment are shown. The first (multiple) dimension experimental results are presented on Figures 3-6, and the learning outcomes dimension results are presented in Figure 7. Graphs include bars with the percentual evaluation for each of the questions.

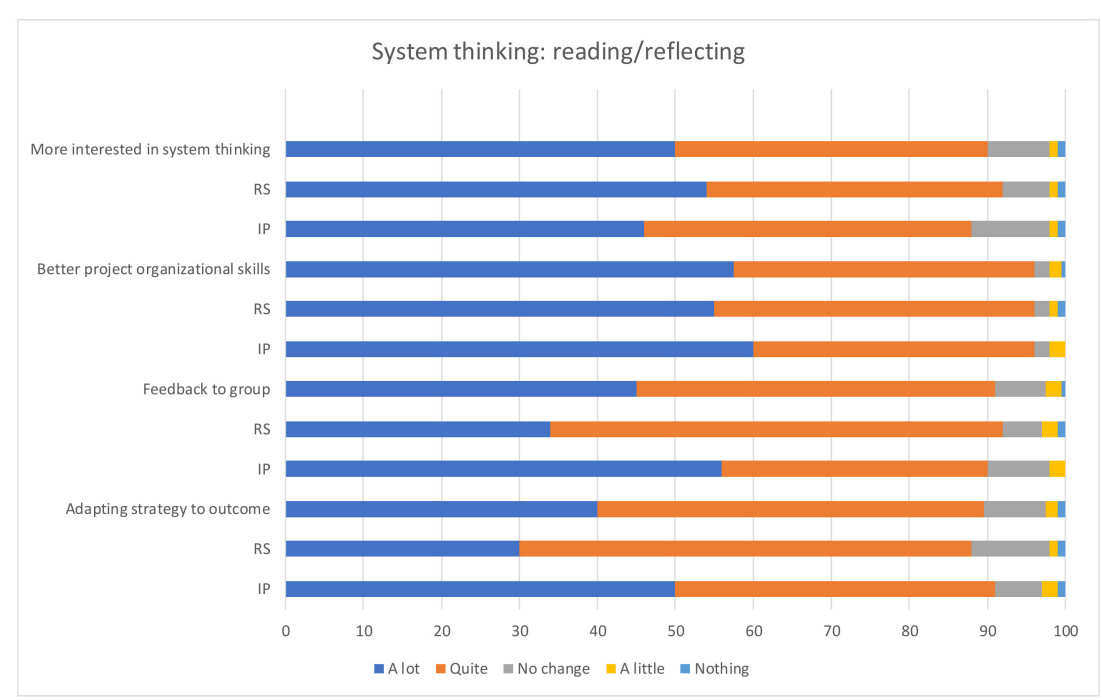

Figure 3. Experience from the whole week (systems thinking: read/reflect). 


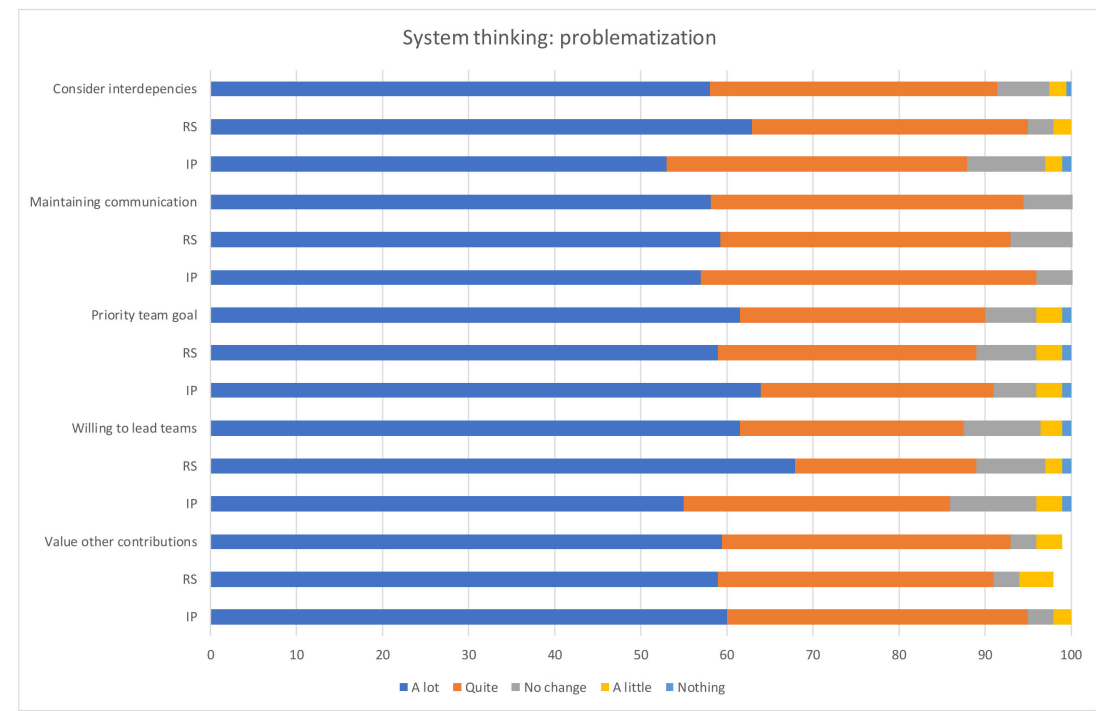

Figure 4. TEL experience from the week (systems thinking: problematization).

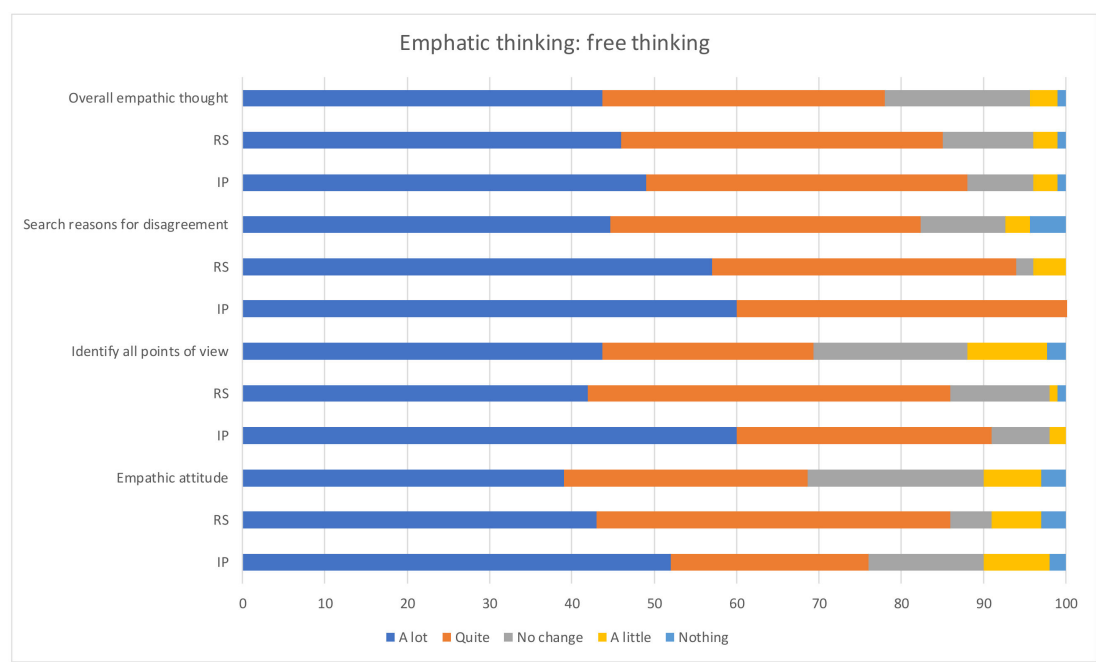

Figure 5. Key learnings (empathic thinking: free solution).

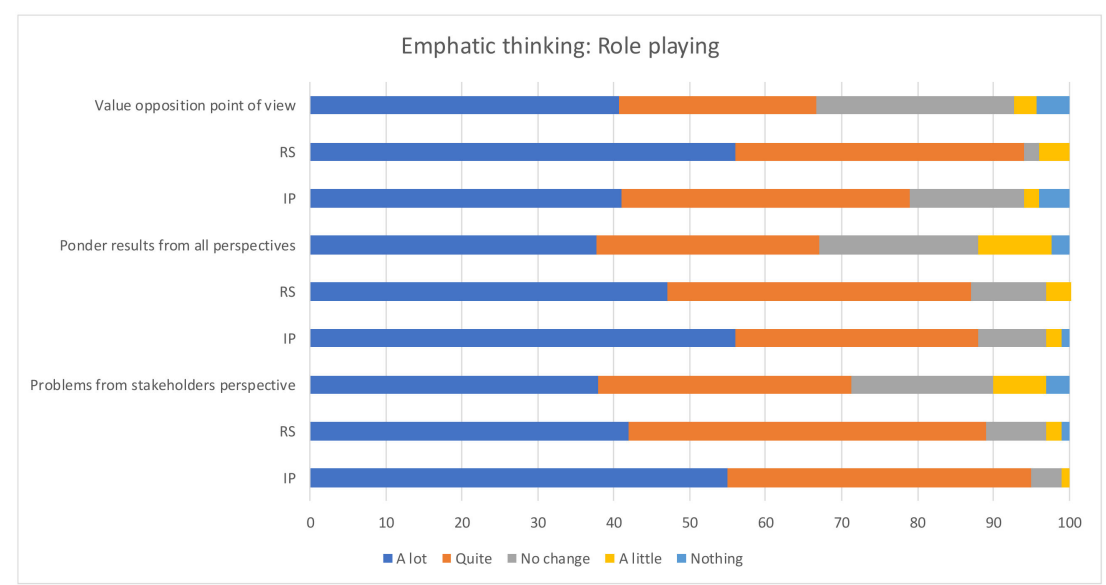

Figure 6. Alternative experiences from the project (empathic thinking: role playing). 


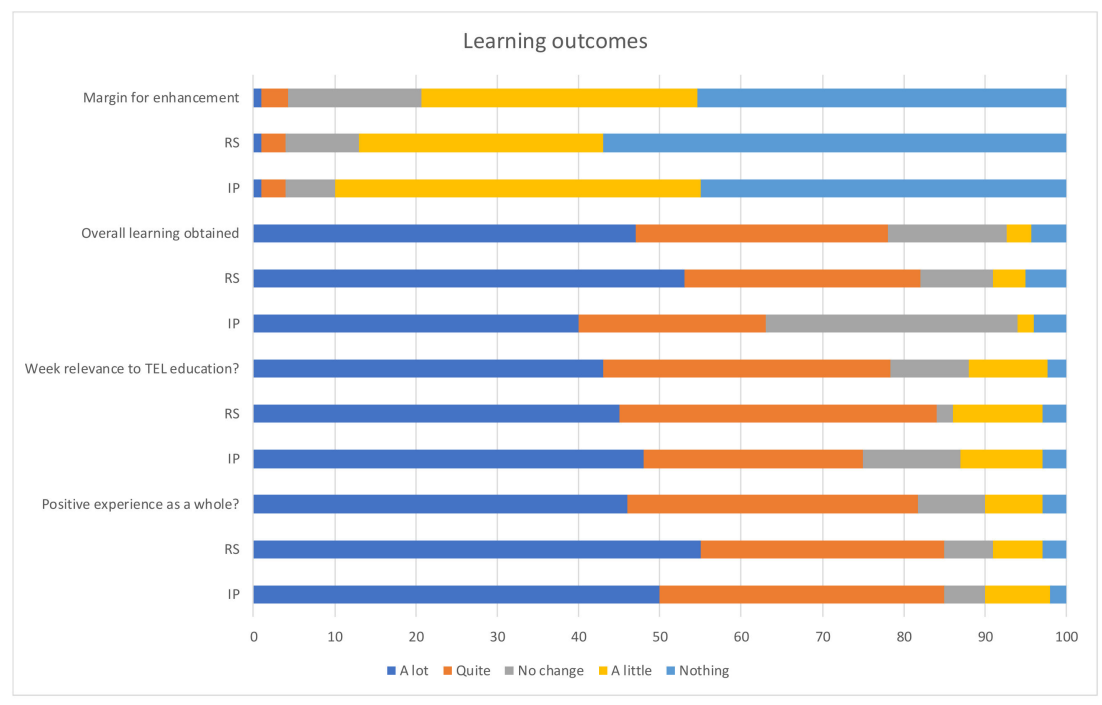

Figure 7. Evaluation of learning outcomes.

As can be seen from all graphs, the implementation analysis is considered very good or good for a very relevant majority of participants, in all courses and dimensions, and with low dispersion (from Table 3). This together with the procedural checks indicate clearly that the results of the pilots were excellent and attained in an efficient way.

Further to the quantitative implementation analysis, the guided debates for all groups allow a more qualitative analysis of the learning outcomes summarized for the relevant topics to be considered for effective knowledge acquisition:

- Interdisciplinarity assessment for the PETRA pilot:

$\bigcirc \quad$ Main progress identified was being able to recognize and articulate TEL as a tool to develop courses collaboratively.

○ Different academic backgrounds, as well as the EU flavor, allowed a higher insight into TEL topics through the confrontation of different perspectives, and avoiding curricular confrontations. Identification of knowledge acquisition encouraged all to be open to differences and open points of view.

- Absence of a shared disciplinary language allowed better problem definitions because different perspectives facilitated simpler approaches and concentrating on finding alternative solutions.

- Due to the transversal course topics, "integration" of disciplines was easier. Participants produced deliverables that would not have been possible independently. Interdisciplinarity was the most important result for all courses.

- Metacognition

- Participants delivered contributions to the project despite being outside their own disciplinary backgrounds. Reflection on this fact promoted a higher satisfaction due to the higher efficiency obtained through group work with TEL as a tool.

$\bigcirc$ Different participants developed individual self-awareness on complementary issues, which was the key for team synergy. Participants were able to confront their attitudes through self-awareness that promoted knowledge acquisition.

- Participants used their individual self-reflections on the debates as a team tool for addressing more creative project solutions. Many participants confessed that the TEL- driven group had a constructive effect for them. Nearly all recognized the synergies of working with people with different ways of thinking through TEL. 
Different planning schemes, tools, and strategies were selected by the groups, producing in all cases the right blend for success. Individual experiences can be developed into larger scales, for identifying different optimal results.

- $\quad$ Systems thinking:

All teams were keen to assess transferable knowledge at group level (through experience and institutional constraints awareness).

Participants were aware of the impacts of the projects at different physical, time, and social scales.

The main concern for all participants was the importance of institutional and country systems issues, as well as their realization of the importance of networking for capacity building.

- Participants identified and worked out solutions not only for financial and physical constraints, but also for transversal knowledge domains to be considered neutrally for developing TEL solutions.

- Empathy:

All participants showed a high level of coherency, probably due to the short course span, common orientation, and missing conflicts, which allowed good strategies for handling disagreement. The lack of a competitive result also prevented important confrontations.

$\checkmark \quad$ All participants excelled in active listening during group work. Upon reflection, TEL promoted this attitude, which was also key for gathering very effective results from the group work.

Synergy was enhanced by the transcendence assumed by participants about the team results. All participants worked proactively for incorporating all different points of view into the debate.

The lack of interactivity imposed by TEL, allowed an ordered personal behavior that resulted in an openness to novel perspectives from all participants, no matter their backgrounds. TEL debates promoted speaking/communicating constructively to achieve the group outcomes. Participants were exposed through an alien environment (TEL) to different academic backgrounds, allowing relevant project co-creation.

\section{Discussion}

The proposed research questions were:

- How can we implement an online collaborative research for excellent results using TEL tools?

- Did the pilot introduce an efficient innovation?

The first question is addressed from the technical implementation perspective. Considering both the platform and the courses required for the joint research pilots, the research implementation met similar experiences in other fields. [22] The TLC plans developed during the PETRA project also helpedtowards an excellent implementation considering current tendencies for equivalent plans in other universities at the initial stage. Also to be noted is that the Internet infrastructure supported the team's work well, due to the freedom of schedules that the pilot allowed.

As for the second research question, the term efficiency has been analyzed from the different factors of the proposed model. The key for an efficient TEL implementation is the promotion of systems thinking in order to develop knowledge transfer, avoiding costly infrastructures. Based on the literature approaches to systems thinking assessment, [23] the conclusions presented show an extraordinary progress on systems thinking development, although it was not formally addressed. This was the basis for the synergy observed on the group discussions. EU moderators reported that this 
"hidden" result was due to the lack of hierarchies, which facilitated open debates. Further evidence of the very positive outcomes for systems thinking is to be found in the project presentations.

The most relevant achievement is the synergy developed through the group projects. The interdisciplinary developments reported from the teams correspond to the "problem solving" category in reference. [24] Despite all participants belonging to the same category (faculty), they represented different disciplines and hierarchic levels at their universities. Not only were there different generations represented, but also very few were familiar with group work for addressing a project. Therefore, although complementary knowledge was present, there was no attitude or experience towards teamwork. Transversal competency development was an aid since nobody had a formal experience on the field, which once again opened the debate. As stated by one EU moderator, "We may have had a far greater and more interesting challenge if we had concentrated on one curricular course."

Also, in alignment with the observations of [24], participants on the PETRA pilot TEL courses agreed on the importance of an EU moderator's involvement in decision making. There seemed to be consensus that foreign points of view sometimes brought light into the project in different ways to the opinions from only one country. All participants agreed that it was essential to develop courses with EU collaboration. In some cases, participants may have had difficulty in understanding EU supervisors' points of view. Cultural differences were on the one hand a burden for group work, but on the other hand this made everybody aware of the need for detailed explanations, which enhanced the project debates. Far from being a hindrance, this boosted a real synergetic result to the TEL knowledge acquisition.

Although similar experiences demonstrate the importance of IT deployment for online education, [25] our approach excelled through the design of the program using IT tools on their higher pedagogical value.

\section{Conclusions}

This paper has demonstrated the efficiency of TEL for curriculum development in Azerbaijan. The team capacity development has been key to the success of the new courses. Consequently, the first official academic application will be addressing an EU cooperation focused on teacher training for widening the future implementation of the methodology.

Efficiency led to an excellent implementation, which included motivation and a good combination of leadership on the supervision. These elements were facilitated by the pilot design and the focus on interdisciplinary project work. Similar results have been demonstrated as key for initial deployment as in the case of South Carolina [22].

The professional development of a university faculty is typically grounded on scientific results. Therefore, scientific paper publication becomes paramount for career promotion. When the main criteria for the teacher's promotion and career advancement neglect teaching, the quality of education suffers. Institutions are required to provide qualification on research competencies for academic staff, which will be the first field of application for the official academic deployment.

The Ministry of Education of the Republic of Azerbaijan will promote the development of official degrees under this methodology thanks to the implementation of the EU-funded project "Support to strengthening the higher education system in Azerbaijan". The aim of the project is to co-create future developments of Azerbaijan's higher education system through the development of TEL courses and degrees. PETRA has contributed to demonstrate the relevance of TEL for the future of higher education institutions. The project implementation period is about to finish, with the following results:

- State standards for 15 pilot programs have been improved and redeveloped to include competence-based and student-centered focuses.

- Quality assurance systems have been developed to reflect the student centeredness of study programs.

- Recommendations on amendments of legislative and regulative framework were also developed. 
Author Contributions: J.O.-M. coordinated all the TEL courses' implementations and developed the analysis together with the EU faculty. A.M.G.-P. extracted the conclusions from the audio recordings obtained on the focus groups' discussions, and J.M.M.-R. post-processed the information obtained through the different surveys. All authors have read and agreed to the published version of the manuscript.

Funding: This research was co-funded by the European Commission through the Erasmus+ KA2 project "Promoting Excellence in Teaching and Learning in Azerbaijani Universities (PETRA)" project number 573630-EPP-1-2016-1-ES-EPPKA2-CBHE-JP.

Conflicts of Interest: The authors declare no conflicts of interest.

\section{References}

1. Fazil, A.; Ward, R. Developing a general extended technology acceptance model for E-learning (GETAMEL) by analysing commonly used external factors. Comput. Hum. Behav. 2016, 56, 238-256.

2. Becker, H.J.; Ravitz, J.L. The influence of computer and Internet use on teachers' pedagogical practices and perceptions. J. Res. Comput. Educ. 1999, 31, 356-384. [CrossRef]

3. Mumford, S.; Dikilitaş, K. Pre-service language teachers reflection development through online interaction in a hybrid learning course. Comput. Educ. 2020, 144, 103706. [CrossRef]

4. Findik-Coskuncay, D.; Alkis, N.; Ozkan-Yildirim, S. A structural model for students' adoption of learning management systems: An empirical investigation in the higher education context. Educ. Technol. Soc. 2018, $21,13-27$.

5. Chen, D.T. Uncovering the provisos behind flexible learning. J. Educ. Technol. Soc. 2003, 6, 25-30.

6. Levine, A.; Sun, J.C. Barriers to Distance Education; American Council on Education: Washington, DC, USA, 2002.

7. Graham, C.R. Blended learning system: Definition, current trends, and future directions. In Handbook of Blended Learning: Global Perspectives; Bonk, C.J., Graham, C.R., Eds.; Pfeiffer Publishing: Zurich, Switzerland, 2004.

8. Lee, D.; Watson, S.L.; Watson, W.R. The Relationships Between Self-Efficacy, Task Value, and Self-Regulated Learning Strategies in Massive Open Online Courses. Int. Rev. Res. Open Distrib. Learn. 2020, 21, $23-39$. [CrossRef]

9. Passey, D. TI-Technology-enhanced learning: Rethinking the term, the concept and its theoretical background. Br. J. Educ. Technol. 2019, 50, 972-978. [CrossRef]

10. Lai, Y.-C.; Peng, L.-H. Effective Teaching and Activities of Excellent Teachers for the Sustainable Development of Higher Design Education. Sustainability 2020, 12, 28. [CrossRef]

11. Lee, S.J.; Lee, H.; Kim, T.T. A Study on the Instructor Role in Dealing with Mixed Contents: How It Affects Learner Satisfaction and Retention in e-Learning. Sustainability 2018, 10, 850. [CrossRef]

12. Ely, S. "Continuous Improvement in Teaching Strategies through Lean Principles". Teaching \& Learning Symposium, University of Southern Indiana. 2016. Available online: http://hdl.handle.net/20.500.12419/455 (accessed on 28 April 2020).

13. Delone, W.H.; McLean, E.R. The DeLone and McLean model of information systems success: A ten-year update. J. Manag. Inf. Syst. 2003, 19, 9-30.

14. Goodman, J.; Melkers, J.; Pallais, A. Can Online Delivery Increase Access to Education? J. Labor Econ. 2019, 37, 1-34. [CrossRef]

15. Alexander, J.; McLachlan, S.; Barcellona, M.; Sackley, C. Technology-enhanced learning in physiotherapy education: Student satisfaction and knowledge acquisition of entry-level students in the United Kingdom. Res. Learn. Technol. 2019, 27. [CrossRef]

16. Eau, G.; Judah, K.; Shahid, H. How Can Adaptive Platforms Improve Student Learning Outcomes? A Case Study of Open Educational Resources and Adaptive Learning Platforms. 2019. Available online: https://ssrn.com/abstract=3478134 (accessed on 2 April 2020).

17. Sun, A.; Chen, X. Online education and its effective practice: A research review. J. Inf. Technol. Educ. Res. 2016, 15, 157-190. [CrossRef]

18. EU Commission. Available online: https://ec.europa.eu/education/education-in-the-eu/digital-educationaction-plan_en (accessed on 27 March 2020).

19. Essence Project. Available online: https://husite.nl/essence/ (accessed on 27 March 2020). 
20. Lönngren, J.; Svanström, M. Systems thinking for dealing with wicked sustainability problems: Beyond functionalist approaches. In New Developments in Engineering Education for Sustainable Development; World Sustainability Series; Leal Filho, W., Nesbit, S., Eds.; Springer: Berlin, Germany, 2016; pp. 151-160.

21. Orozco-Messana, J.; de la Poza-Plaza, E.; Calabuig-Moreno, R. Experiences in Transdisciplinary Education for the Sustainable Development of the Built Environment, the ISAlab Workshop. Sustainability 2020, 12, 1143. [CrossRef]

22. Ranwala, D.; Alberg, A.J.; Brady, K.T.; Obeid, J.S.; Davis, R.; Halushka, P.V. Retreats to Stimulate Cross-Disciplinary Translational Research Collaborations: Medical University of South Carolina CTSA Pilot Project Program Initiative. In Strategies for Team Science Success; Hall, K., Vogel, A., Croyle, R., Eds.; Springer: Berlin, Germany, 2019.

23. Tan, T.; Nesbit, S.; Ellis, N.; Ostafichuk, P. Crossing boundaries: Developing transdisciplinary skills in engineering education. In Proceedings of the Canadian Engineering Education Association (CEEA) Conference, Vancouver, BC, Canada, 3-6 June 2018; Volume 107, pp. 1-18.

24. NAS; NAE; IOM. Facilitating Interdisciplinary Research; National Academy of Sciences: Washington, DC, USA; National Academy of Engineering: Washington, DC, USA; Institute of Medicine: Washington, DC, USA; The National Academies Press: Washington, DC, USA, 2005; Volume 306, p. 188.

25. Kurilovas, E.; Kubilinskiene, S. Lithuanian case study on evaluating suitability, acceptance and use of IT tools by students-An example of applying Technology Enhanced Learning Research methods in Higher Education. Comput. Hum. Behav. 2020, 107. [CrossRef]

(C) 2020 by the authors. Licensee MDPI, Basel, Switzerland. This article is an open access article distributed under the terms and conditions of the Creative Commons Attribution (CC BY) license (http://creativecommons.org/licenses/by/4.0/). 